\title{
A UNIVERSIDADE PÚBLICA E OS DESAFIOS POSTOS A FORMAÇÃO EM SERVIÇO SOCIAL NO BRASIL
}

\section{THE PUBLIC UNIVERSITY AND THE CHALLENGES POSED FOR THE TRAINING IN SOCIAL WORK IN BRAZIL}

\author{
Raquel Santos Sant'Ana ${ }^{1}$ \\ Onilda Alves do Carmo ${ }^{2}$ \\ Fátima Grave Ortiz ${ }^{3}$
}

\section{RESUMO}

Este artigo propõe discutir o projeto de formação profissional no Serviço Social brasileiro e a relação com as universidades. Atualmente, as universidades públicas brasileiras estão sofrendo com os resultados de uma forte crise política e econômica, que traz várias dificuldades e obstáculos para o desenvolvimento da graduação e da pós-graduação. Certamente estas questões desafiam a universidade e a vida acadêmica nas suas três dimensões: ensino, pesquisa e extensão. Este panorama incide sobre o Serviço Social e seu projeto profissional.

PALAVRAS-CHAVE: Serviço Social. Universidade. Formação Profissional.

\begin{abstract}
This paper aims to discuss the professional training project in Brazilian Social Work area and the relation with Universities. Nowadays, the Brazilian Public Universities are struggling with the results from a hard political and economical crisis environment, which brings several difficulties and obstacles for the colleges and post-graduation courses development. Surely, these questions challenge the university and academic life in its three dimensions: teaching, research and extension program. This panorama refers to Social Work and its professional project.
\end{abstract}

KEYWORDS: Social Work. University. Professional Training.

\footnotetext{
${ }^{1}$ Professora da Faculdade de Ciências Humanas e Social de Franca- UNESP. Presidente Nacional da Associação Brasileira de Ensino e Pesquisa em Serviço Social (ABEPSS), gestão Ousadia e Sonhos em tempos de resistência, biênio 2015/2016. E-mail: raquelssfranca@yahoo.com.br.

${ }^{2}$ Professora da Faculdade de Ciências Humanas e Social de Franca- UNESP. Membro da direção Nacional da ABEPSS, gestão Ousadia e Sonhos em tempos de resistência, biênio 2015/16. E-mail: onildalves@uol.com.br.

${ }^{3}$ Professora da Escola de Serviço Social e do Programa de Pós-Graduação em Serviço Social da Universidade Federal do Rio de Janeiro. Membro da direção Nacional da ABEPSS, gestão Ousadia e Sonhos em tempos de resistência, biênio 2015/16. E-mail: fgrave@oi.com.br.

Serv. Soc. \& Saúde, Campinas, SP v.15, n. 1 (21), p. 15-36, jan.jun. 2016 ISSN 1676-6806
} 


\section{INTRODUÇÃO}

Em 2016, o Serviço Social brasileiro completa 80 anos. Uma profissão jovem, mas que em sua trajetória histórica conseguiu construir um legado teórico metodológico e ético político que permite pensar o trabalho, a pesquisa e a formação numa perspectiva crítica, voltada para interesses emancipatórios.

Promover uma formação baseada em referências teóricas e políticas que seguem na contramão do projeto societário hegemônico tem se colocado como um desafio permanente. A produção científica e tecnológica, bem como a concepção de universidade, estão em permanente disputa e, nessa sociabilidade, se sobrepõem os ideários de um projeto de desenvolvimento que corresponde, sobretudo, aos interesses do capital. A essas dificuldades se somam as condições atuais da educação superior no Brasil, cujo processo de mercantilização tem desencadeado, de maneira massiva, a precarização da formação profissional.

É nesse complexo movente e contraditório que esse artigo problematiza a universidade e a direção dada ao ensino e a pesquisa, principalmente nesse contexto em que ocorre a expansão e precarização da formação superior na Brasil. A ênfase do debate sobre a formação ocorre a partir do curso de Serviço Social e dos desafios presentes no âmbito da graduação e da pós-graduação.

\section{A UNIVERSIDADE E A PRODUÇÃO DO CONHECIMENTO NA SOCIEDADE CAPITALISTA}

Em pleno século XXI, os avanços científicos e tecnológicos são considerados componentes fundamentais da sociabilidade, pois permitiram o recuo das barreiras naturais e o desenvolvimento das forças produtivas. Entretanto, as controvérsias sobre a direção social desse desenvolvimento ultrapassam os espaços da universidade a medida que as consequências desse processo atingem a humanidade como um todo. Ainda que o discurso ideologizado coloque todo e qualquer processo de desenvolvimento como sinônimo de "desenvolvimento capitalista", na realidade, esses termos não são equivalentes. O desenvolvimento pode se dar em muitas direções, tendo em vista que Serv. Soc. \& Saúde, Campinas, SP v. 15, n. 1 (21), p. 15-36, jan./jun. 2016 ISSN 1676-6806 
promover a potência humana, respeitar a natureza e preservar o planeta devem (ou deveriam) ser suas premissas fundamentais. Se seguirmos em direção contrária e isso é fato, temos que discutir se o processo de desenvolvimento em curso pode ser chamado assim, ou pelo menos se ele não deve ser qualificado como "desenvolvimento capitalista", mesmo que em seu interior existam tendências e produções voltadas para perspectivas contrárias a sua lógica destrutiva.

O Brasil é um país marcado por profundas desigualdades econômicas e sociais, típicas das sociedades regidas pelo capital e com as particularidades de um país com inserção subalterna na economia mundial e com um Estado transnacionalizado. As classes dominantes desse país não realizaram a transição típica da chamada "revolução burguesa" e aliaram seus interesses ao projetos da burguesia internacional, mesmo que isso tenha lhes colocado numa condição de dependência e instabilidade econômica.

Daí a facilidade do avanço das ideias neoliberais na década de 1990, ainda que apropriadas segundo as determinações dadas pela realidade brasileira: o Estado se tornou mínimo para a garantia dos direitos sociais, porém continuou forte para a sustentação das atividades produtivas e para os subsídios ao capital.

Nesse período, ocorre em âmbito mundial, uma ampla reestruturação das atividades produtivas desencadeada pela chamada terceira revolução industrial promovida pelo avanço da robótica e da microeletrônica, o que permitiu o aprofundamento do processo de mundialização do capital e contribuiu para o acirramento das ideias neoliberais. Os rebatimentos dessas mudanças para a classe trabalhadora são devastadores: dificuldade de mobilização e organização política, aumento da precarização e intensificação do trabalho, recuo de direitos $\mathrm{e}$ empobrecimento generalizado.

No Brasil, segundo Boito Júnior,

[...] foi nesse quadro marcado, de um lado, por dificuldades crescentes para o movimento sindical e popular e, de outro lado, pelo fato de um setor da burguesia começar a rever suas posições frente a algumas das chamadas reformas orientadas para o mercado que se criaram as condições para a construção de uma frente política que abarcasse setores das classes dominantes e das classes dominadas. Essa frente, organizada, fundamentalmente, pelo PT chegou ao poder governamental em 2003 com a posse do primeiro Governo Lula (BOITO JUNIOR, 2002, p. 2). 
Ainda que a expectativa de grande parte da classe trabalhadora com relação ao Governo Lula fosse que ele retomasse um projeto de desenvolvimento e fizesse avançar os direitos sociais, na realidade, o pacto político conservador que o levou ao governo não dava sustentação para uma inversão de rota do projeto em curso. O modelo de desenvolvimento econômico aprofunda as normas e os ditames do programa neoliberal, implantado na década de 1990, procurando, entretanto, conter algumas distorções, implementando políticas de erradicação da fome por meio de programas de transferência de renda e de recuperação do salário mínimo. Para Castelo (2012), Lula assumiu o governo afirmando que o abandono ao neoliberalismo teria ocorrido por meio de "transição progressiva e pactuada", ocultando com quem esse pacto havia sido feito. "Vale dizer, o pacto foi selado com as novas e antigas classes dominantes (capital financeiro e suas novas frações rentistas e o agrobusiness) que participam do bloco de poder em posições de destaque [...]" (CASTELO, 2012, p. 627).

Nesse período, começa-se a se esboçar a ideia de que se estaria em curso uma nova etapa do desenvolvimentismo (PEREIRA, 2004, apud CASTELO, 2012). Este novo desenvolvimentismo seria uma estratégia de desenvolvimento nacional como forma de romper com neoliberalismo ortodoxo. Os debates sobre esse tema foram bastante amplos e marcados fundamentalmente por dois posicionamentos: de um lado os que defendem que o aquecimento da economia, a melhoria nas condições de vida da população e ampliação de seu poder de compra são evidências de uma nova etapa desenvolvimentista; de outro aqueles que contestam que esse período possa ser chamado de desenvolvimentista, pois não houve aquecimento da economia digno de nota, que a melhoria nos indicadores sociais se deu pela redistribuição da renda do trabalho, que a ampliação dos direitos sociais ficaram restritos aos programas focalizados de renda destinados os segmentos mais pauperizados enquanto a maioria dos direitos sociais continuaram sendo vilipendiados, que o aumento do emprego significou aumento da trabalho precarizado, entre outros.

Sampaio Junior, um dos autores que contesta a tese de que está em curso um novo projeto de desenvolvimento, afirma: “o neodesenvolvimentismo é um rótulo oco. É muito mais uma estratégia de propaganda dos governos Lula e Dilma, para se diferenciar dos governos FHC, do que um corpo de doutrina para orientar a ação do Estado" (SAMPAIO JR, 2012, p. 2). 
A ausência de uma perspectiva totalizante da política econômica não permite que os defensores do novo desenvolvimentismo percebam a complexidade da teia institucional que ata de maneira inescapável o Estado brasileiro aos interesses do grande capital internacional e nacional e estes à perpetuação da dupla articulação - dependência externa e segregação social (SAMPAIO JUNIOR, 2012, p. 682).

$\mathrm{Na}$ realidade, o modo de produção capitalista principalmente a partir de sua ideologia neoliberal, tem desencadeado grandes paradoxos e o acirramento de profundas e perversas desigualdades entre os diversos países e entre as diferentes classes sociais. A lógica produtiva promove fenômenos extremos, inéditos em outras sociabilidades, como o desenvolvimento de tecnologia de ponta capaz de detectar doenças em fetos, de nomear sequências genéticas e alterá-las segundo seus interesses ou necessidades. Mas, contraditoriamente populações inteiras morrem de fome devido à apropriação privada das imensas riquezas socialmente produzidas. Jean Ziegler, ex-consultor da ONU afirma:

A destruição anual de dezenas de milhões de homens, mulheres e crianças pela fome constitui o escândalo de nosso século. A cada cinco segundos, morre uma criança de menos de dez anos. Em um planeta que, no entanto, transborda de riquezas... No seu estado atual, a agricultura mundial poderia alimentar sem problemas 12 bilhões de seres humanos - vale dizer, quase duas vezes a população atual. Quanto a isto, pois, não existe nenhuma fatalidade. Uma criança que morre de fome é uma criança assassinada (ZIEGLER, 2013, p. 21).

A apropriação privada e o desperdício colocam-se como elementos que contribuem sobremaneira para a destruição anual de seres humanos como apontado por Ziegler. Segundo a FAO, dados de 2013, 1,3 bilhão de toneladas de alimentos vão para o lixo todos os anos. Ao mesmo tempo 870 milhões de pessoas passam forme. Esse desperdício no mundo causa enorme perda econômica, e tem impacto significativo nos recursos naturais dos quais a humanidade depende para se alimentar ${ }^{4}$.

Desta forma, pensar a universidade como o lócus privilegiado da produção do conhecimento científico e tecnológico no atual contexto histórico pressupõe considerar a direção social dada a essa produção. Há que se perguntar qual a contribuição do conhecimento produzido no sentido de reverter as diversas desigualdades exemplificadas, no caso aqui, no quadro da fome no mundo e os seus impactos,

\footnotetext{
${ }^{4}$ Disponível no site https://nacoesunidas.org/dia-mundial-do-meio-ambiente-deste-ano-reforcacampanha-contra-o-desperdicio-de-alimentos/. Acessado em 04 de março de 2016.

Serv. Soc. \& Saúde, Campinas, SP v.15, n. 1 (21), p. 15-36, jan./jun. 2016 ISSN 1676-6806
} 
conforme apontado pela ONU? Quais pesquisas estão sendo produzidas e que interesses elas atendem?

Apreender a função social da universidade, em especial da universidade pública, exige pensar a própria lógica que orienta a produção científica, afinal com qual conceito de desenvolvimento trabalham as ciências e as universidades? Distinguimos "desenvolvimento capitalista" de "desenvolvimento", ou trabalhamos como se fossem um único conceito? Produzimos ciência e tecnologia para permitir a emancipação humana ou para viabilizar a sociedade do capital e sua lógica destrutiva voltada fundamentalmente para ao lucro?

A universidade surge, desde seus primórdios, como uma instituição reconhecida e legitimada publicamente, comprometida com as ideias de formação, reflexão, criação e crítica (CHAUÍ, 2000). Contudo, nas últimas décadas, a universidade vem perdendo, cada vez mais, seu caráter universal de instituição social para tornar-se uma organização social, responsável por oferecer ao mercado a força de trabalho requisitada pelas atividades produtivas diretamente ligadas a reprodução dos interesses capitalistas, bem como produzir pesquisas e conhecimentos cujo objetivo último é o de contribuir para a produção e reprodução do capital.

Chauí (2000) em seus escritos sobre a universidade destaca a relação desta com a realidade e os diversos interesses políticos que permeiam a produção do conhecimento. A autora destaca que as mudanças no perfil da universidade são resultado das relações instituídas na atual ordem econômica e social, as quais fazem com que ela passe de "instituição social" para "organização social". A partir de então, a universidade passa a ter outra forma de se organizar:

Ela é regida pelas ideias de gestão, planejamento, previsão, controle e êxito. Não lhe compete discutir ou questionar sua própria existência, sua função, seu lugar no interior da luta de classes [...] a instituição social aspira à universalidade, se percebe inserida na divisão social e política e busca definir sua universalidade (ou imaginária ou desejável) que lhe permita responder às contradições impostas pela divisão. Ao contrário, a organização pretende gerir seu espaço e tempo particulares aceitando como dado bruto sua inserção num dos polos da divisão social, e seu alvo não é responder às contradições, e sim vencer a competição com seus supostos iguais (CHAUÍ, 2000, p. 32). 
A passagem da universidade de "instituição social" para "organização social" atende à lógica da produção do desenvolvimento capitalista na medida em que cada vez mais direciona a ciência à tecnologia para viabilizar a reprodução ampliada dessa lógica societária. Um exemplo desse processo, dentre muitos outros que poderiam ser aqui enumerados, é a direção social da produção de tecnologias para a agricultura, cuja ênfase majoritária é voltada para a resolução dos problemas desencadeados por essa forma de organização da produção que se caracteriza pelo o cultivo em larga escala de um único produto com utilização de insumos químicos e maquinaria pesada, típico da grande agricultura capitalista. Romeiro (2007) discute a irracionalidade dessa lógica produtiva e destaca:

Pode-se dizer que a evolução do padrão tecnológico que caracteriza as práticas agrícolas modernas foi condicionada, em grande medida, pela necessidade de contornar os impactos ecológicos negativos da monocultura. Nesse sentido, as práticas agrícolas modernas não foram como afirmam seus defensores, a resposta mais eficiente para aumentar a produtividade da terra e do trabalho agrícola. Foram sim a resposta mais eficiente para aumentar a produtividade em determinado contexto socioeconômico e institucional. Do ponto de vista estritamente tecnológico teria sido possível modernizar a agricultura com base em outro padrão, mais equilibrado do ponto de vista ecológico (ROMEIRO, 2007, p. 298).

Diversas outras características da produção científica atual poderiam ser enumeradas para evidenciar a sua direção social e política, mas o que interessa destacar nesse artigo é que a ciência e a universidade em geral não podem ser analisadas de forma endógena ou neutra, e sim a partir do contexto histórico no qual estão inseridas.

Daí o fato da reflexão sobre o gênero humano e o debate sobre os fundamentos da ciência e da tecnologia, nessa sociedade sustentada pela ordem sócio metabólica do capital monopolista, cada vez mais ficarem dispersos. Em seu lugar, conhecimentos rápidos e ágeis para um mercado fluído e virtual, típicos desse momento histórico, são enaltecidos.

É importante destacar, no entanto que, se existe um projeto societário hegemônico que sustenta esta concepção de conhecimento, isso quer dizer que existem outros que disputam esse espaço. Essa assertiva é verdadeira para a sociabilidade, mas também para a ciência e para a universidade onde diferentes projetos estão em disputa. E nesse processo, a disputa dentro da universidade pública é estratégica e fundamental 
para a construção de uma massa crítica que possa disputar a hegemonia com outra proposta de desenvolvimento, voltada para interesses de fato emancipatórios.

Desde 1996, quando da aprovação da Lei de Diretrizes e Bases da Educação (Lei 9394/96), a educação brasileira passa por profundas mudanças. O Estado irá aprofundar a entrada do capital na oferta de cursos de nível universitário, como já havia feito no ensino secundário ou de nível médio, além de regular, com mais precisão a modalidade do ensino à distância. O processo de mercantilização do ensino superior vai sendo fortalecido ao longo dessas duas décadas e, hoje grandes conglomerados educacionais estrangeiros se organizam como universidades ou centros tecnológicos com objetivo maior de conseguir maiores lucros, parte desses auferidos com fundo público pela via de recursos advindos do Fundo de Investimento na Educação Superior (FIES) ${ }^{5}$.

A entrada do capital na Educação Superior pode ser ilustrada pela presença dos Fundos de Investimento que tem capital aberto negociados nas bolsas de valores e que se fundem para abarcar um mercado ainda maior:

[...] as transações comerciais efetivadas entre o Fundo americano Carlyle e a Vince Capital Gestora de Recursos às quais giraram em torno de R $\$ 850$ milhões. Os executivos justificam a compra porque consideram que há uma demanda reprimida por educação universitária à distância em torno de 12 milhões de pessoas devido às medidas restritivas do FIES (Boletim Valor Econômico, 01 de março de $2016)^{6}$.

O resultado desse processo tem sido devastador para a formação superior e em especial para o Serviço Social que é o segundo curso mais ofertado na modalidade Ensino à Distância no Brasil. A amplitude do desmonte da formação em Serviço Social desencadeado pelo ensino à distância e mesmo por cursos presenciais orientados pela lógica mercantil é algo que preocupa sobremaneira as entidades organizativas do Serviço Social ${ }^{7}$, em especial a Associação Brasileira de Ensino e Pesquisa de Serviço

\footnotetext{
${ }^{5}$ O FIES foi instituído no governo FHC em 1999, ampliado no Governo Lula; ele substituiu o Crédito Educativo criado em 1976 pelo Governo Militar.

${ }^{6}$ Os fundos finalizaram ontem a compra do Grupo Uniasselvi por R $\$ 850$ milhões, sendo que R $\$ 400$ milhões foram pagos à vista. O restante do valor será pago em parcelas iguais corrigidas pela variação do IPCA. A transação prevê ainda o pagamento de R \$ 255 milhões adicionais condicionados ao cumprimento de metas financeiras.

${ }^{7}$ Em atenção a tais preocupações, as entidades do Serviço Social - CFESS, ABEPSS e ENESSO construíram coletivamente o Plano de Lutas em Defesa do Trabalho e da Formação e contra a Precarização do Ensino Superior com o objetivo de encaminhar ações conjuntas para o enfrentamento da conjuntura deletéria que se constitui para o mundo do trabalho e para a formação profissional.

Serv. Soc. \& Saúde, Campinas, SP v. 15, n. 1 (21), p. 15-36, jan./jun. 2016 ISSN 1676-6806
} 
Social (ABEPSS), que tem procurado discutir a importância da universidade pública e de seu tripé composto do ensino, pesquisa e extensão na formação em Serviço Social.

\section{A UNIVERSIDADE PÚBLICA E O TRIPÉ ENSINO, PESQUISA E EXTENSÃO}

A universidade pública, ainda que marcadamente influenciada por concepções hegemonizadas pelas classes dominantes, é ainda reduto possível de produção científica e tecnológica comprometida com o desenvolvimento humano e social. É nesse espaço que o tripé ensino, pesquisa e extensão pode se articular para promover uma formação de qualidade, não do ponto de vista da eficiência ou eficácia ditada pelo capital, mas no sentido de permitir que a produção do conhecimento seja fundamento para a construção de um patamar civilizatório onde a emancipação humana seja o princípio orientador do modelo de desenvolvimento. Nela as atividades fundamentais devem estar intrinsecamente vinculadas ao caráter de instituição pública, vinculadas a um projeto histórico-político emancipatório que sirva à nação e que preserve os valores éticos e culturais. A universidade ainda que com contradições é um espaço de resistência a um processo devastador que a tudo submete por meio de mecanismos alienantes em que o Estado se coloca como o guardião das regras do mercado (LEOPOLDO e SILVA, 2001).

Segundo Leopoldo e Silva (2001) a universidade como instituição pública pode e deve assumir a função de garantir o efetivo caráter público de que se revestem os bens de cultura historicamente legados ao presente, ao menos daqueles que não pertencem diretamente ao capital comercial. No entanto, a partir do ideário neoliberal, no espaço da universidade brasileira acirram-se as disputas entre os vários projetos.

No Brasil, a universidade definida como lugar da ciência e da produção do conhecimento, a partir da Constituição de 1988 em seu artigo 207, passa a obedecer ao princípio da indissociabilidade entre ensino, pesquisa e extensão ${ }^{8}$. Wanderley destaca a importância da Universidade:

[...] a universidade é um lugar - mas não só ela - privilegiado para conhecer a cultura universal e as várias ciências e divulgar o saber, mas deve buscar uma identidade própria e uma adequação à realidade

\footnotetext{
${ }^{8}$ Conforme o artigo 207 da Constituição Federal brasileira: "Art. 207. As universidades gozam de autonomia didático-científica, administrativa e de gestão financeira e patrimonial, e obedecerão ao princípio de indissociabilidade entre ensino, pesquisa e extensão".

Serv. Soc. \& Saúde, Campinas, SP v.15, n. 1 (21), p. 15-36, jan./jun. 2016 ISSN 1676-6806
} 
nacional. Suas finalidades básicas são o ensino, a pesquisa e extensão. Ela é a instituição social que forma, de maneira sistemática e organizada, os profissionais, técnicos e intelectuais de nível superior que as sociedades necessitam (WANDERLEY, 1983, p. 11).

A extensão universitária ainda que componente essencial do tripé universitário, historicamente foi e continua sendo a área com menos investimento público. Na década de 1980, em função das pressões exercidas pelos movimentos sociais e pelos segmentos críticos da universidade, institui-se o Fórum de Pró-Reitores de Extensão das Universidades Públicas que aprovaram um Plano Nacional de Extensão, cuja vigência se deu até 2011. Nesse Plano, a diretriz política favorece uma perspectiva de extensão universitária como troca de saberes:

Neste, sob a influência das ideias de Paulo Freire (1992), a Extensão foi definida como ação institucional voltada para o atendimento das organizações e populações, com um sentido de retroalimentação e troca de saberes acadêmico e popular. Nessa perspectiva, as camadas populares deixaram de ser o objeto para se tornarem o sujeito da ação extensionista, denotando, assim, avanços significativos em relação à noção de Extensão Universitária construída na década anterior (NOGUEIRA, 2005, apud Fórum de Pró-Reitores de Extensão das Universidades Públicas Brasileiras, maio de 2012, p. 8).

Essa ação instalada num processo de "abertura gradual e restrita" aponta a extensão universitária, ainda que com limites estruturais, como um processo que articula o ensino e a pesquisa e que promove uma ação transformadora entre universidade e sociedade.

Desde a aprovação do Plano de Extensão até os dias atuais muita coisa foi se modificando na relação da universidade com a sociedade. Merece destaque a aprovação dos Fundos Intersetoriais, criados em 1999, que permitiram o recebimento de contribuições das empresas para as pesquisas tecnológicas desenvolvidas pela universidade. As consequências desse processo são amplas e extravasam os objetivos desse texto, no entanto, vale ressaltar que essas parcerias entre universidade pública e empresas trouxeram rebatimentos diretos sobre a pesquisa e a extensão e, viabilizaram a apropriação e uso da pesquisa e do conhecimento públicos por interesses privados, o que significa de fato, privatização da universidade pública.

Por outro lado, o que se observa é que, embora haja um avanço no debate sobre o tripé ensino-pesquisa-extensão, este fica afeito às universidades públicas e numa perspectiva claramente privatizante. Para aquelas universidades privadas que funcionam Serv. Soc. \& Saúde, Campinas, SP v. 15, n. 1 (21), p. 15-36, jan./jun. 2016 ISSN 1676-6806 
como empresas ligadas ao setor educacional, o tripé é sempre incipiente e/ou voltado para uma perspectiva mercantil.

Em 2011 foi aprovado o novo Plano Nacional de Extensão com vigência até 2020 e que, na realidade, referenda as diversas práticas extensionistas existentes dentro da universidade e que não eram contempladas pelo Plano anterior, o qual sintonizava a extensão com uma relação transformadora com a sociedade e os movimentos sociais. Agora a extensão é considerada uma atividade acadêmica que viabiliza a troca de saberes e está voltada não mais para as lutas sociais e, sim para a erradicação de pobreza. É o que está descrito nas metas 03 e 04 do PNExt 2001-2020 :

Meta 3: Organizar, até 2012, redes e consórcios de universidades públicas para atuação em articulação com o governo federal em programas de erradicação da miséria e promoção do desenvolvimento social nos municípios de maior prioridade.

Meta 4: Articular, até 2013, ao menos um programa institucional de extensão em cada universidade pública articulado com as políticas de erradicação da Fome e da Miséria conduzidas pelo governo (PNExt2011-2020, p. 2-3).

Ainda que prevaleça na extensão universitária um compromisso com a prestação de serviços à comunidade ou de assessoria e pesquisa para grandes empresas e grupos econômicos (uma das formas de privatização da universidade pública), grupos minoritários seguem existindo e construindo outras formas de trabalho que se orientam por uma concepção de extensão universitária em que a troca de saberes entre o popular e o acadêmico constitui o ponto nevrálgico e formativo para os sujeitos envolvidos; um espaço político de crítica às diversas formas de hierarquização do saber e de questionamento das relações dominação e de opressão política e cultural ${ }^{9}$.

Esses grupos disputam a direção social da universidade, aliás, são a evidência que diferentes projetos subsistem dentro desse espaço e se fazem presentes no seu tripé: no ensino, na pesquisa e na extensão universitária.

Mas é importante não desconsiderar que a crise econômica que perpassa as universidades públicas coloca ainda novos desafios para toda a comunidade acadêmica e seus projetos de formação. Um dos desafios é a Emenda Constitucional que propõe a

\footnotetext{
${ }^{9}$ Exemplos desse tipo de extensão na Faculdade de Ciências Humanas e Sociais de Franca (campus da UNESP) são os grupos que se colocam como praticantes da extensão comunicativa: Núcleo Agrário Terra e Raiz (NATRA), Grupo Margarida Alves, Grupo de Alfabetização Paulo Freire, só para mencionar aqueles que são coordenados por docentes do curso de Serviço Social.

Serv. Soc. \& Saúde, Campinas, SP v.15, n. 1 (21), p. 15-36, jan./jun. 2016 ISSN 1676-6806
} 
mudança na Constituição para possibilitar que as universidades públicas possam cobrar mensalidade nos cursos de pós-graduação latu sensu, extensão e profissionalização ${ }^{10}$. Embora a emenda mantenha a gratuidade nos cursos regulares de graduação e pósgraduação stricto sensu, mantendo as estruturas da universidade, isto significaria, no limite, o avanço intensivo e extensivo do processo de privatização.

Há que se acrescentar que o processo de privatização do ensino superior iniciado no governo FHC cresceu de forma exponencial nos governos Lula. O projeto de democratização do ensino superior transformou, de fato, na expansão do ensino privado, incluindo aí a modalidade de Ensino à Distância.

O REUNI - Programa do Governo Federal de Apoio a Planos de Reestruturação e Expansão das Universidades Federais Brasileiras, foi criado em 2007 com o objetivo de dar condições às instituições de expandir o acesso e garantir condições de permanência estudantil. Ainda que seja digna de nota a expansão das universidades públicas no Governo Lula, ela vai se dar sem os recursos necessários para a manutenção da qualidade do ensino, pesquisa e extensão, bem como sem o crescimento compatível da permanência estudantil que é de fato um programa essencial para que os estudantes pobres possam permanecer na Universidade.

O maior investimento, no entanto, dar-se-á pela expansão do ensino privado por meio de incentivo do FIES que significou, no limite, o endividamento da classe trabalhadora e a ampliação das possibilidades de maiores lucros para as empresas educacionais.

É nessa realidade complexa e contraditória que trazemos o debate sobre a formação em Serviço Social e a importância da universidade pública para a efetivação das diretrizes curriculares da Associação Brasileira de Ensino e Pesquisa em Serviço Social (ABEPSS) $)^{11}$.

\footnotetext{
${ }^{10}$ PROPOSTA DE EMENDA À CONSTITUIÇÃO N. ${ }^{0}$ 395-A, DE 2014 (Do Sr. Alex Canziani e outros) Altera a redação do inciso IV do art. 206 da Constituição Federal, referente à gratuidade do ensino público em estabelecimentos oficiais; tendo parecer da Comissão de Constituição e Justiça e de Cidadania, pela admissibilidade (relator: DEP. OSMAR SERRAGLIO). Disponível no site www2.camara.leg.br/proposicoesWeb/fichadetramitacao?idProposicao. Acesso em 11 de março de 2016. ${ }^{11} \mathrm{~A}$ ABEPSS reconhece que a crise econômica e a lógica privatista do ensino superior está presente também nas universidades estaduais, em particular na UNESP, que desde 1977 possui o Curso de Serviço Social. O avanço do processo de precarização do trabalho docente, bem como os cortes orçamentários, tiveram forte rebatimento nos programas de permanência estudantil e nos projetos de extensão.

Serv. Soc. \& Saúde, Campinas, SP v. 15, n. 1 (21), p. 15-36, jan./jun. 2016 ISSN 1676-6806
} 


\section{O SERVIÇO SOCIAL E SEU PROJETO ÉTICO-POLÍTICO}

O Serviço Social brasileiro em 2016 completa 80 anos. Uma profissão jovem, mas que ao longo de sua história construiu um legado teórico metodológico e uma opção ético-política numa perspectiva crítica, voltada para a defesa de um projeto de sociedade sustentado em ideais emancipatórios.

Desde seu surgimento na década de 1930 até o contexto atual, o Serviço Social promoveu um giro ideológico e político que permitiu, especialmente nos últimos 35 anos, que a profissão e as suas entidades representativas construíssem no âmbito do trabalho e da formação uma direção social voltada para princípios democráticos e para a defesa de uma sociedade sem exploração e opressão.

Foi a partir de 1980 que o Serviço Social avançou formalmente no sentido de construir referências teóricas que permitiram a profissão o entendimento do antagonismo de classe presente nas sociedades capitalistas e as particularidades da sociedade brasileira marcada por profundas desigualdades econômicas, sociais, culturais. A identificação da particularidade de sua inserção na divisão social e técnica do trabalho e do significado político da profissão, bem como seu autorreconhecimento como trabalhador assalariado, fez com que o Serviço Social assumisse o compromisso com valores emancipatórios, para os quais a classe trabalhadora assume a missão revolucionária de alcançá-los. Na realidade, nessa década e nas posteriores foi sendo construído um conjunto de referências teórico-metodológicas, ideo-políticas e técnico instrumentais para subsidiar a ação, a produção e a formação profisssional em uma dada direção. Esse constructo teórico e ideo-político é chamado de Projeto Ético-Político profissional e expressa a imagem que os assistentes sociais desejam afirmar socialmente. Netto (1999) ao referir-se aos projetos profissionais assim os definem:

[...] os projetos profissionais apresentam a autoimagem de uma profissão, elegem os valores que a legitimam socialmente, delimitam e priorizam seus objetivos e funções, formulam os requisitos (teóricos, práticos e institucionais) para o seu exercício, prescrevem normas para o comportamento dos profissionais e estabelecem as bases das suas relações com os usuários de seus serviços, com as outras profissões e com as organizações e instituições públicas (inclusive o Estado, a que cabe o reconhecimento jurídico dos estatutos profissionais). (NETTO, 1999, p. 4). 
É evidente que uma profissão que atua diretamente vinculada as refrações mais graves do embate estabelecido entre capital trabalho, em uma sociedade cujos interesses dos trabalhadores permanecem historicamente subsumidos aos do capital, a afirmação de um projeto profissional que defende ideais libertários e que se posiciona contrariamente a todas as formas de exploração e opressão vigentes na sociedade capitalista irá enfrentar muitas dificuldades de efetivação e até de aceitação por parte do conjunto dos profissionais de Serviço Social. Como afirma Marx, as ideias da classe dominante são sempre dominantes para o conjunto da sociedade. Isso tem rebatimento direto sobre todas as propostas que se contrapõem aos princípios hegemônicos presentes na sociabilidade, nas ciências, ou nas profissões, como é o caso do projeto profissional do Serviço Social.

A incorporação de novos valores e princípios não ocorre de maneira uníssona ou consensual, aliás, pelo contrário: a direção social da profissão e da formação estão em permanente disputa. Mas o legado crítico tem possibilitado ao Serviço Social brasileiro condições de fazer a defesa de direitos de cidadania e, ao mesmo tempo, posicionar-se a favor da construção de outra sociabilidade.

No projeto profissional a liberdade é entendida como valor ético fundamental, pois é condição para plena expansão dos indivíduos sociais; a democracia, a cidadania como realização de direitos civis, políticos e sociais e a qualidade dos serviços prestados são defesas incontestes da profissão. Porém, ainda que o Serviço Social defenda e se comprometa com as lutas pela emancipação política, entende que a supressão da exploração e diversas expressões da opressão, só serão possíveis numa outra sociabilidade para além do capital, ou seja, que a emancipação humana plena exige a construção de outra forma de viver em sociedade.

É evidente que uma profissão não poderá ser definida de maneira endógena e o Serviço Social, como todas as outras profissões, se faz a partir da materialidade de sua inserção na divisão social e técnica do trabalho; suas produções teóricas irão dialogar com os referenciais científicos e a formação será, em grande medida, definida a partir dos processos que instituem e definem o Ensino Superior no Brasil nos diversos momentos históricos.

O projeto ético-político, que expressa a autoimagem da profissão, será tensionado de maneira incisiva nos diversos espaços sócio-ocupacionais e, em algumas Serv. Soc. \& Saúde, Campinas, SP v. 15, n. 1 (21), p. 15-36, jan./jun. 2016 ISSN 1676-6806 
circunstâncias, as dificuldades irão se sobrepor as possibilidades de práticas emancipatórias. Num cenário regressivo como vivenciado nos últimos tempos, isso tende a ser bastante evidenciado. Forti e Guerra (2015) destacam que,

Há pelo menos 30 anos tem se buscado construir no serviço social, em confronto com os discursos e práticas conservadoras, uma imagem social orientada por uma perspectiva crítica e por valores, princípios, diretrizes, pautas e concepções teórico metodológicas que se expressam na formação, na pesquisa, no conhecimento produzido e nas lutas encampadas pelas entidades da categoria. Não obstante o acúmulo de forças [...], não tem havido grandes alterações no que se refere ao exercício profissional cotidianamente. Ao contrário, nesses espaços temos identificado um avanço do neoconservadorismo, ao mesmo tempo em que há um aprofundamento da crise do capital e das suas estratégias de destruição em massa, que comportam a retirada de direitos sociais e trabalhistas, a precarização das condições e relações de trabalho e o aniquilamento das lutas coletivas (FORTI; GUERRA 2015, p. 1).

Ora se a materialidade da vida é fundamental para a percepção dos sujeitos sobre a sua realidade, é evidente que num contexto marcado pela quase ausência de um projeto societário emancipatório em condições de disputar ideologicamente "mentes e corações" como o projeto burguês, a prevalência no âmbito político de perspectivas conservadores na sociedade e nas profissões é consequência quase óbvia desse processo. Mas exatamente porque essa realidade é contraditória e permeada de conflitos e antagonismos que é possível a uma profissão como o Serviço Social resistir e lutar para que a direção social crítica tenha incidência sobre a produção do conhecimento, $o$ trabalho profissional e a formação.

Devido aos limites desse texto, iremos nos reportar as características dos embates, disputas e conquistas que tem sido possível efetivar no âmbito da formação profissional. Procurar-se-á evidenciar a importância da universidade pública e de seu tripé composto de ensino, pesquisa e extensão para a permanência e consolidação do projeto de formação do Serviço Social brasileiro e de sua direção libertária.

\section{OS DESAFIOS DA FORMAÇÃO EM SERVIÇO SOCIAL}

Quando no III Congresso Brasileiro de Assistentes Sociais (CBAS), ocorrido em 1979, o Serviço Social brasileiro girou sua direção política e realizou uma profunda crítica ao tradicionalismo e ao conservadorismo presentes historicamente na profisssão, observa-se que tal giro teve implicações em várias dimensões que incidem sobre o Serv. Soc. \& Saúde, Campinas, SP v.15, n. 1 (21), p. 15-36, jan./jun. 2016 ISSN 1676-6806 
exercício e a formação profissional. Do mesmo modo, a partir dessa data, as entidades da categoria serão assumidas por representantes dessa tendência nominada por Netto (1991) de "intenção de ruptura" que, aos poucos, vão promovendo uma ampla reformulação naquelas dimensões citadas linhas atrás.

Do ponto de vista da formação profissional, os primeiros passos na construção de um renovado projeto de formação profissional se deram a partir da constituição do currículo mínimo de 1982, que como sabemos ainda que com imprecisões, expressou a ruptura com o tripé caso, grupo e comunidade.

Mais de uma década depois e resultado do acúmulo teórico-político de parte da categoria profissional expresso no projeto ético-político, a construção das Diretrizes Curriculares, aprovadas pela ABEPSS em 1996, sustentam-se nos aportes da Teoria Social Crítica (esta apoiada no pensamento marxiano) e indicam que a formação profissional deve considerar o Serviço Social como uma totalidade, e neste sentido, determinado historicamente e atravessado por múltiplas determinações de natureza econômica, política, cultural e ideológica. Tal concepção exige a constituição de um profissional com clara perspectiva crítica, ciente do processo histórico brasileiro e suas relações com o capitalismo mundial, das particularidades assumidas pelas classes sociais no Brasil e pelo Estado, que sem eliminar os traços arcaicos, modernizou-se no trato das expressões da "questão social”, combinando repressão com políticas sociais.

Deste modo, as Diretrizes Curriculares aprovadas pela ABEPSS indicam um determinado perfil profissional, que deve ser pretendido pela formação:

Profissional que atua nas expressões da questão social, formulando e implementando propostas para seu enfrentamento, por meio de políticas sociais públicas, empresariais, de organizações da sociedade civil e movimentos sociais. Profissional dotado de formação intelectual e cultural generalista crítica, competente em sua área de desempenho com capacidade de inserção criativa e propositiva no conjunto das relações sociais e no mercado de trabalho. Profissional comprometido com os valores e princípios norteadores do Código de Ética do Assistente Social (ABEPSS, 2007, p. 227, destaque nosso).

Além disso, articulado a este perfil, as Diretrizes Curriculares indicam um conjunto de competências e habilidades necessárias para a consolidação deste, bem como princípios para a formação e uma nova lógica curricular com a indicação dos núcleos de fundamentos teórico-metodológicos da vida social, de fundamentos da 
formação sócio-histórica da sociedade brasileira e de fundamentos do trabalho profissional e seus conteúdos curriculares (ABESS, 1997).

Entretanto, apesar dos avanços, as Diretrizes Curriculares aprovadas em assembleia da ABEPSS em 1996 foram profundamente impactadas pelas supressões realizadas durante o processo de sua aprovação pelo Conselho Nacional de Educação, gerando o que comumente chamamos de "diretrizes do MEC".

Assim, as Diretrizes Curriculares aprovadas em 2001 pelo MEC excluíram aspectos importantes indicados na proposta original da Comissão de Especialistas ${ }^{12}$, apresentada em 1999 ao MEC, por meio de sua Secretaria de Educação Superior. A então detalhada proposta de Diretrizes Curriculares foi duramente esvaziada pelo MEC, que excluindo-lhe aspectos estratégicos e decisivos para a articulação das diversas dimensões do Serviço Social (teórico-metodológica, ético-política, técnico-operativa e investigativa), tendeu a fragilizar o projeto de formação profissional para a nossa área e sua orgânica relação com o projeto ético-político profissional.

A supressão dos traços críticos presentes nas Diretrizes Curriculares demonstra claramente como a ofensiva conservadora presente na contemporaneidade, que atinge as políticas sociais de um modo geral e à Educação Superior e o Serviço Social em particular.

Soma-se a isso, o franco processo de precarização da educação superior, marcadamente constituída em nosso país pela esfera privada, que cresce exponencialmente e se torna cada vez mais alvo de investimento dos grandes oligopólios (como afirmado linhas atrás); além das iniciativas governamentais quanto à reestruturação das universidades federais materializado pelo REUNI (Programa de Reestruturação das Universidades Federais).

Conforme dados da Plataforma E MEC (http://emec.mec.gov.br/ acesso em fevereiro de 2016), há 3.468 ofertas de cursos de Serviço Social no Brasil entre unidades presenciais de formação acadêmica e polos da modalidade ensino à distância. A mesma Plataforma indica que dentre essas ofertas, há uma concentração massiva na modalidade à distância com 2.946 polos contra 522 unidades de formação presenciais.

\footnotetext{
${ }^{12}$ A comissão de especialistas foi formada a época pelas professoras Marilda Villela Iamamoto, Maria Bernadete Martins Pinto Rodrigo e Mariângela Belfiore Wanderley.

Serv. Soc. \& Saúde, Campinas, SP v.15, n. 1 (21), p. 15-36, jan./jun. 2016 ISSN 1676-6806
} 
Defendemos a incompatibilidade da modalidade à distância para a formação em Serviço Social para a primeira graduação em função das características que essa modalidade de ensino tem assumido em nosso país. A lógica mercantil tem prevalecido na oferta dos cursos, sem a necessária preocupação com o processo formativo e isso pode ser evidenciado pelo número de irregularidades constatadas nesses cursos pelas entidades de Serviço Social (conjunto CFESS/CRESS, ABEPSS e ENESSO) ${ }^{13}$. É importante destacar ainda que consideramos o tripé ensino, pesquisa e extensão como fundamentais para a efetivação das diretrizes curriculares, o que não acontece nos cursos de EAD. A isso se soma a necessidade de uma interlocução permanente e do debate para que o estudante possa adentrar conhecimentos densos e voltados para uma perspectiva que irá exigir opção ético política, o que se torna inviável a distancia e sem interlocução coletiva. O aligeiramento, os projetos pedagógicos sem sintonia sequer com as diretrizes curriculares do MEC, os estágios irregulares, a ausência de supervisão acadêmica, tutores sem qualificação exigida para o processo formativo são apenas alguns elementos constatados nesses cursos e que tem exigido das entidades de Serviço Social o claro posicionamento contrário ao ensino à distância no Serviço Social.

Entretanto, se no âmbito da graduação os desafios são muitos, na pós-graduação os mesmos também não são menores.

Os recentes cortes nas verbas de capital e custeio dos programas pela CAPES e os constantes atrasos no repasse dos recursos colocam em xeque a excelência que as mesmas agências exigem. No entanto, se observa a prevalência do lançamento de editais voltados à formação de quadros nas empresas privadas ou ao desenvolvimento de tecnologias direcionadas aos interesses das empresas (a lei 13243 de 11 de janeiro de 2016 que dispõe do novo marco legal da ciência, tecnologia e inovação é um bom exemplo).

Com poucos recursos e muitas exigências, o cotidiano dos programas, de suas coordenações, do corpo docente e discente tende a ser bastante tenso e com muita dificuldade de se construir coletivamente consensos. Dentre as muitas tensões, registrase a intensa busca pelo cumprimento dos prazos de conclusão dos cursos de pósgraduação, que tende a ser incompatível, sobretudo considerando o perfil e a relação

\footnotetext{
${ }^{13}$ A esse respeito conferir as publicações das entidades sobre a incompatibilidade entre graduação à distância e Serviço Social.

Serv. Soc. \& Saúde, Campinas, SP v. 15, n. 1 (21), p. 15-36, jan./jun. 2016 ISSN 1676-6806
} 
estabelecida entre os estudantes de pós-graduação e os programas. As coordenações dos diversos programas de pós-graduação em Serviço Social tem relatado uma mudança do perfil de nossos estudantes, que cada vez mais pauperizados, precisam se inserir no mercado de trabalho em face ao número irrisório de bolsas.

Outra tensão, diz respeito à necessidade progressiva de produção dos programas e seus sujeitos, docentes e discentes, para o alcance dos critérios exigidos pela avaliação. Contudo, esta produção deve ser o resultado de nossas pesquisas, que ainda são majoritariamente isoladas. Há profícuas experiências de programas que estão tentando articular suas pesquisas por meio dos editais PROCAD (Programa Nacional de Cooperação Acadêmica da CAPES), mas ainda são poucas as iniciativas por várias razões. A limitação e a concorrência dos editais em função dos cortes de recursos, a sobrecarga de trabalho e a consequente indisponibilidade dos docentes e pesquisadores, sem dúvida, são fatores que incidem sobre este tímido número de experiências e iniciativas.

Com efeito, as dificuldades que incidem sobre a graduação, o fazem também sobre o universo da pós-graduação, aprofundando os desafios e inflexões ao processo de ruptura com o histórico conservadorismo que o Serviço Social brasileiro tenta superar nas últimas décadas.

\section{CONSIDERAÇÕES FINAIS}

Desde os anos 1980, o Serviço Social brasileiro defende um conjunto de princípios e valores que reconhece na classe trabalhadora aquela capaz de realizar a transformação da sociedade. O reconhecimento da liberdade como valor ético central, a defesa da cidadania, da democracia e da equidade social como meios para consolidação de uma nova ordem societária, bem como o empenho na eliminação de toda a forma de preconceito e autoritarismo e a defesa dos direitos humanos consistem em princípios ético-políticos que devem orientar as ações e reflexões dos assistentes sociais brasileiros, que para isso precisam contar com uma formação crítica e de qualidade.

Entendemos que apenas um ambiente universitário que assegure a indissociabilidade ensino-pesquisa-extensão será capaz de garantir as condições objetivas e subjetivas para a constituição de um perfil profissional crítico, competente e Serv. Soc. \& Saúde, Campinas, SP v.15, n. 1 (21), p. 15-36, jan./jun. 2016 ISSN 1676-6806 
comprometido com tais princípios. Portanto, consideramos que processos políticos e econômicos que incidem sobre as universidades de modo à precarizá-las, esvaziando politicamente suas funções maiores na produção do conhecimento, não contribuem com a constituição do perfil profissional que desejamos. Ao contrário, tende a inviabilizar seu caráter crítico e restringir suas potencialidades.

No entanto, considerando a direção social e estratégica que nosso projeto de formação profissional defende e persegue, entendemos que o Serviço Social pode contribuir expressivamente para o fortalecimento da universidade pública, participando das disputas pela democratização dos espaços intra-universitários e acadêmicos.

Recebido em 16.03.2016 - Aprovado em 06.06.2016

\section{REFERÊNCIAS}

ABEPSS. Associação Brasileira de Ensino e Pesquisa em Serviço Social. Revista Temporalis, Ano VII, n. 14, São Luís, jul./dez. 2007.

BOITO JUNIOR, A. As bases políticas do neodesenvolvimentismo. Trabalho apresentado na edição de 2012 do Fórum Econômico da FGV / São Paulo. Disponível e acessado em 10 de março de 2016 no site:

http://eesp.fgv.br/sites/eesp.fgv.br/files/file/Painel\%203\%20-

\%20Novo\%20Desenv\%20BR\%20-\%20Boito\%20-\%20Bases\%20Pol\%20Neodesenv\%20-

\%20PAPER.pdf

CASTELO, R. O novo desenvolvimentismo e a decadência ideológica do pensamento econômico brasileiro. Serviço Social \& Sociedade. São Paulo, n 112, p. 613-636, out./dez. 2012.

CFESS/CRESS; ABEPSS; ENESSO. Sobre a Incompatibilidade entre graduação a distância e Serviço Social. Brasília/DF. 2012.

CHAUÍ, M. A Universidade Operacional. In: Cadernos de Textos. $1^{\text {a }}$ Assembleia Universitária da UNESP. Campus de Bauru-SP, de 30/03 à 02/04/2000, p. 31-34.

FORTI, V., GUERRA,Y. Apresentação. In: FORTI,V.; GUERRA,Y. (orgs). O Projeto ético político do Serviço Social: contribuições a sua crítica. Coletânea Nova de Serviço Social. Rio de Janeiro: Lumen Juris. 2015, p. 1-4. 
LEOPOLDO E SILVA, F. Reflexões sobre o conceito e a função da universidade pública. Revistas Estudos Avançados - USP, vol. 15, 2001. Disponível no site www.revistas.usp.br/eav/article/download/9807/11379. Acessado em 10/03/2016.

MARX, K.; ENGELS, F. A Ideologia Alemã. São Paulo: Boitempo, 2007.

NETTO, J. P. Ditadura e Serviço Social: uma análise do Serviço Social no Brasil pós-64. São Paulo: Cortez, 1991.

NETTO, J. P. A construção do projeto ético-político do Serviço Social frente à crise contemporânea. Capacitação em Serviço Social e Política Social: crise contemporânea, questão social e Serviço Social. Brasília, DF: CEAD, módulo 1, p. 93-128, 1999.

NOGUEIRA, 2005, apud Fórum de Pró-Reitores de Extensão das Universidades Públicas Brasileiras, maio de 2012, p.8).

PFEIFER, M. Bresser-Pereira e o pacto neodesenvolvimentista. Temporalis, [S.1.], ano 13, n. 26, p. 11-36, jul./dez. 2013. Disponível em: $<$ http://periodicos.ufes.br/temporalis/article/view/6066>. Acesso em: 10 mar de 2016.

ROMEIRO, A. R. Perspectivas para políticas agroambientais. In: RAMOS, P. (Org.). Dimensões do agronegócio brasileiro: políticas, instituições e perspectivas. Brasília: MDA, 2007, p. 283-317.

SAMPAIO JR, P. Vivemos um processo de reversão neocolonial. Entrevista concedida à IHU On-Line, Revista do Instituto Humanitas Unisinos, n. 392 - Ano XII 14/05/2012. Disponível no site http://www.ihuonline.unisinos.br/media/pdf/IHUOnlineEdicao392.pdf em 10 de março de 2016.

SAMPAIO JR, P. Desenvolvimentismo e neodesenvolvimentismo: tragédia e farsa. Serviço Social \& Sociedade. São Paulo, nº 112, p. 672-688, out./dez. 2012.

SANT'ANA, R. S., CARMO, O. A. A Extensão Universitária e os processos de avaliação. In: POZZER, M. R. O. (org.) A Extensão Universitária e Economia da Cultura: a experiência em universidades públicas brasileiras. São João Del Rei: Malta, 2012 .

ZIEGLER, J. Destruição em massa geopolítica da fome. São Paulo: Cortez, 2013.

WANDERLEY, L. E. O que é universidade. São Paulo/SP: Editora Brasiliense, 1983. 


\section{Sites pesquisados:}

http://periodicos.bc.unicamp.br/ojs/index.php/sss/about/submissions\#onlineSubmissions http://welbergontran.com.br/cliente/uploads/4c5aafa072bcd8f7ef14160d299f3dde29a66 d6e.pdf acesso em 07/03/2016.

Valor Econômico, 01/03/2016. Fundos buscam negócios de educação para comprar.

http://www.valor.com.br/search/apachesolr search/\%22KROTON\%22?solrsort=created \%20desc. Acessado em 05/03/2016.

http://www.redebrasilatual.com.br/ambiente/2015/06/onu-chama-atencao-paradesperdicio-de-alimentos-no-mundo-e-pede-mudancas-6494.html. Acessado em 05/03/2016.

https://nacoesunidas.org/dia-mundial-do-meio-ambiente-deste-ano-reforca-campanhacontra-o-desperdicio-de-alimentos/. Acessado em 10/03/2016.

https://nacoesunidas.org/dia-mundial-do-meio-ambiente-alerta-para-o-desperdicio-decomida/. Acessado em 10/03/2016. 